\title{
Assortative mating on risk attitude
}

\author{
Philomena M. Bacon • Anna Conte • \\ Peter G. Moffatt
}

Published online: 12 July 2014

C The Author(s) 2014. This article is published with open access at Springerlink.com

\begin{abstract}
Spousal correlation in risk attitude is estimated using data from the German Socio-Economic Panel over the period 2004-2009. We apply the bivariate panel ordered probit model to the analysis of the simultaneous determination of the male's and the female's risk attitude, using the survey question about general willingness to take risk, provided on a $0-10$ Likert-scale. The correlations between both the individual-specific effects of the two partners and the two within-individual errors are separately estimated, and found to be +0.285 and +0.310 , respectively. We consider the former to be a key parameter, since its positive sign may be interpreted in terms of positive assortative mating on risk attitude: individuals tend to form partnerships with others having a similar risk attitude. We also find evidence that this correlation increases with years of marriage, suggesting either a form of spousal socialization or a selection process in which marriage breakdown is more likely in poorly matched couples.
\end{abstract}

Keywords Multiple equation models - Ordinal data $\cdot$ Panel data $\cdot$ Risk attitude Assortative mating $\cdot$ Spousal correlation $\cdot$ Homophily

P. M. Bacon

School of Environmental Sciences, University of East Anglia, Norwich NR4 7TJ, UK

\section{A. Conte}

Strategic Interaction Group, Max Planck Institute of Economics, Kahlaische Str. 10, 07745 Jena, Germany

e-mail: aconte@econ.mpg.de; contea@westminster.ac.uk

\section{A. Conte}

EQM Department, University of Westminster, 35 Marylebone Road, London NW1 5LS, UK

P. G. Moffatt ( $\square)$

School of Economics, University of East Anglia, Norwich NR4 7TJ, UK

e-mail: p.moffatt@uea.ac.uk 


\section{JEL Classification $\quad$ C $33 \cdot D 81$}

\section{Introduction}

There is an enduring fascination with marriage and the ingredients of its success both at the personal and societal level. In the words of Ribar (2004) "Marriage is positively associated with a large number of outcomes including improved cognitive, emotional and physical well-being for children, better mental and physical health for adults, and greater earnings for family members". 1 The hazards inherent in the increase in the divorce rate in Western societies are also clear (Light and Ahn 2010): for example, the consequent increase in the number of single-adult households gives rise to greater competition for housing and other resources. Clearly there are many dimensions in which marriage stability has economic implications.

Becker (1974), in his theory of marriage, considers factors that induce the stability of marriage over time. In this context, he points to assortative mating ${ }^{2}$ which focuses on the attributes each party seeks in the other: "men differing in physical capital, education or intelligence (aside from their effects on wage rates), height, race, or many other traits will tend to marry women with like values of these traits". 3

There is much empirical evidence relating to Becker's assortative mating hypothesis. Many of these works find spousal correlation in observable anthropometric features, for example Belot and Fidrmuc (2010), Oreffice and Quintana-Domeque (2010), Chiappori et al. (2012a), Hitsch et al. (2010), Kooreman (1994), Kano (2008) and McPherson et al. (2001). Others pursue similar goals with regard to health and wellbeing (Powdthavee 2009; Wilson 2002), smoking behavior (Chiappori et al. 2012b; Clark and Etilé 2006), and personality traits (Dupuy and Galichon 2012).

In this paper, we consider empirically the extent of assortative mating on the trait of risk attitude. Risk attitude may play a different sort of role in the matching process from the traits listed above, because risk sharing arguments might lead to the prediction that risk seekers form partnerships with risk averters, that is, to the prediction of negative assortative mating or disassortative mating (Chiappori and Reny 2006).

Bateman and Munro (2005) and Abdellaoui et al. (2013) obtain experimental data on, respectively, 76 and 60 married couples, but find no evidence of spousal correlation, positive or negative, in risk attitude. However, further experimental evidence, although not involving married couples, due to Di Cagno et al. (2012) leads to the conclusion that when subjects are allowed to choose a gambling partner, they tend to team up with other agents displaying similar degrees of risk aversion. They interpret this as a form of homophily (McPherson et al. 2001): the tendency of individuals to form partnerships with others having similar personality traits.

In many ways, the laboratory is the ideal testing ground for the type of hypothesis in which we are interested. Crucially, the laboratory allows control over the experimental

\footnotetext{
1 Ribar (2004), p. 1.

2 Although Becker refers to this as "assortive mating" (p. 311), the term "assortative mating" is now more widely used.

3 Becker (1974), p. 326.
} 
setting, one important means of exercising such control being in the use of task-related incentives. However, it is possible to pursue the same objectives using a different type of data source: a longitudinal survey with self-reported risk attitude questions. Although use of such a source clearly forfeits the levels of control enjoyed in the laboratory, the potential benefits are considerable. Most obviously, the number of respondents participating in surveys is typically much higher than the number of subjects engaging in an experiment, and the sample is more likely to be representative of the wider population. The benefits in terms of statistical power from using a larger more representative sample are well known. Moreover, the time-dimension of the survey typically extends over a meaningful time horizon, facilitating the identification of within-individual variation and other key parameters.

One such survey is the German Socio-Economic Panel (SOEP), in which individuals report risk attitude on a $0-10$ Likert-scale (Likert 1932). The resulting variable has already been analyzed by Dohmen et al. (2011, 2012). This data source is used in the present paper to investigate how individual-specific risk attitude enters the matching process leading to couple formation. To our knowledge, scant attention has been paid to the estimation of spousal correlation in risk attitude using survey data. An exception is Dohmen et al. (2012), who uncover a positive relationship between male and female risk attitude using linear regression techniques. The current paper builds on that contribution in a number of ways. First our objective is to investigate the way in which the two spouses' risk attitudes are jointly determined, since this is consistent with the concept of "assortative mating." We approach this by specifying two equations, one for each partner, and focusing on the correlation between the error terms. Hence, we avoid any notion of the direction of causality in risk attitude, from male to female, or vice versa, which is unavoidable in the context of a single linear regression equation.

Second, we fully respect the ordinality of the responses, implicit in Likert-scale data, using the ordinal regression model as a basic framework. ${ }^{4}$

Third, the panel structure of the data enables us to estimate separately two different correlation parameters, which may be interpreted in the context of Becker's (1973) theory of marriage. The first $\left(\rho_{u}\right)$ represents the correlation between individual-specific terms for the two partners and may be interpreted in terms of the extent of "assortative mating"; the second $\left(\rho_{\epsilon}\right)$ represents the correlation between the two within-individual errors and may be interpreted in terms of "shared social environment". We consider the first of these $\left(\rho_{u}\right)$ to be of particular relevance, since it conveys information on the matching process; specifically, it reveals whether risk-seeking individuals match with other risk-seeking individuals (if $\rho_{u}>0$ ), or with risk-averse individuals (if $\rho_{u}<0$ ). If $\rho_{u}=0$, we may conclude that risk attitude is irrelevant in the matching process. Furthermore, by estimating $\rho_{u}$ separately by sub-sample, we are able to investigate the extent of socialization, that is, the tendency for members of a couple to grow more similar with years of marriage.

Finally, we develop a new estimation framework, the bivariate panel ordered probit model (BPOP), that is suitable for the separate estimation of these two correlation parameters. Smith and Moffatt (1999) have drawn attention to the problems arising

\footnotetext{
4 If linear regression is used, the ordinal responses are being treated as cardinal, and this is well known to lead to biases in estimation (Daykin and Moffatt 2002).
} 
in the estimation of correlation parameters in limited dependent variable settings. In particular, they find that it is very hard to obtain a precise estimate when only crosssection bivariate binary data are available. This underlines the usefulness of the ordinal data that are available on self-reported risk attitude, and the importance of exploiting the full range of ordinal responses. Furthermore, it is important to make maximal use of the repeated responses. It is for all of these reasons that we develop and estimate the BPOP, a framework that we expect to be useful to other researchers.

The paper is organized as follows. Section 2 describes the data. Section 3 outlines the theory underlying the BPOP model which is used for estimation. Section 4 presents and interprets the estimation results. Section 5 concludes.

\section{The data}

We draw on data from the SOEP for the four years 2004, 2006, 2008 and 2009. There are approximately 21,000 individuals, surveyed on average 3.2 times in the four survey years. For the purposes of this research, a subset of "household couples" is extracted from the panel, comprising 7,761 couples, observed on average 3.1 times over the four years.

In constructing the couples dataset a number of items were taken into account. From the variable "relationship to head" we determine the "head" and "spouse" for each household for each survey year. We are careful to check that they both report having a partner or being married (referring to the variable denoting marital status). This filtering rule excludes: elderly parent heads who have older children living with them; households headed by single heads; and "non-head" households, in which the spouse remains following separation, divorce or bereavement. The variable denoting gender is then used to identify couples with male heads, and couples with female heads. We do not find any same-gender couples.

The dependent variable in our analysis is on the generic risk attitude question asked in each of the survey years. This question is reproduced as follows:

"How do you see yourself? Are you generally a person who is fully prepared to take risks or do you try to avoid taking risks?" Please tick a box on the scale, where 0 means "risk averse" and the value 10 means "fully prepared to take risks"

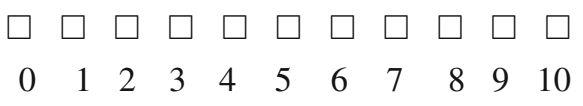

One potential problem with self-reported data on risk attitude is that responses are not incentive compatible. This concern has been allayed to some extent by Dohmen et al. (2011) who find a strongly positive relationship between self-reported risk and choices made in incentivised choice problems. A second potential problem with the analysis of self-reported risk is the possibility of measurement error: Likert-scale responses are dictated partly by the "response style" of respondents. Here, we appeal to Dittrich et al. (2007) who establish that to include a random-effects component, as 
we do in our model, is sufficient to capture inter-respondent differences in response style.

There is another possible source of measurement error, arising from our use of the generic risk measure in preference to the domain-specific risk measures (financial, health, etc.) that are also available within the SOEP database. One obvious potential problem with the generic measure is the possibility that the two members of a couple have different types of risk in mind when responding to the general risk question. Our principal reason for working with the generic measure is a practical one: this is the only measure which is observed at a sufficient number of separate time-points per couple, for identification of our model's parameters to be feasible. However, we have other compelling reasons for this choice of measure. Once again we appeal to Dohmen et al. (2011) who find that risk attitudes are strongly correlated across contexts, and who also use principal components analysis to find evidence of the existence of a single trait governing risk taking in all contexts. They furthermore find that, of all risk measures, the generic risk measure is the best all-round predictor of actual risky behavior. The usefulness of the generic risk measure is further confirmed by its success in explaining actual behavior in several recent applied studies (see for example, Bonin et al. 2007; Jaeger et al. 2010).

A number of explanatory variables feature in the model. Age (in years) and agesquared are used in order to allow for a non-monotonic age effect. The variable representing educational attainment contains four levels: none recorded; less than high school; high school; more than high school. From this we extract a dummy variable to denote whether the individual has a higher education level than their spouse. The occupation variable is converted into four dummy variables: unemployed; self-employed; retired; and other occupation (being the base case). For each of these we include the status of both in each equation for example: "female is self-employed" and "male is self-employed." The variable "presence of children in the HH" denotes the presence of children aged 17 or under in the household. Log of household income is derived from the income of all family members reported for the survey year, including benefits. This income figure is applied to both members of the couple. The time variable indicates the month number in which the interview takes place, taking values between 1 (January 2004) and 72 (December 2009).

\section{Bivariate panel ordered probit (BPOP) model}

The ordered probit model was introduced by Aitchison and Silvey (1957) and extended to repeated outcomes by Frechette $(2001 \mathrm{a}, \mathrm{b})$. In this paper, we make the further extension that is necessary when repeated ordered outcomes are observed simultaneously for two different agents; we refer to this extended model as the BPOP model. The main scope of this section is to derive the log-likelihood function for the BPOP model. For this purpose, we shall focus on the empirical example considered in the paper: the simultaneous modeling of the risk-attitude of male and female partners.

Let $i$ index couples $i, i=1, \ldots, n$, and let $t$ index time period, $t=1, \ldots, T$. Let $y_{m, i t}$ be the response (to the risk question) of the male in couple $i$ in period $t$, and let $y_{m, i t}^{*}\left(-\infty<y_{m, i t}^{*}<+\infty\right)$ be that male's underlying latent propensity to risk-taking. 
Let $y_{f, i t}$ and $y_{f, i t}^{*}$ be similarly defined for the female in couple $i$ in period $t . y_{m, i t}$ and $y_{f, i t}$ may take values $1, \ldots, J, J$ being the length of the Likert scale. Let $x_{m, i t}$ and $x_{f, i t}$ be vectors of explanatory variables pertaining to the male and the female, respectively, at time $t$.

We then specify two equations:

$$
\begin{aligned}
& y_{m, i t}^{*}=x_{m, i t}^{\prime} \beta_{m}+u_{m, i}+\epsilon_{m, i t} \\
& y_{f, i t}^{*}=x_{f, i t}^{\prime} \beta_{f}+u_{f, i}+\epsilon_{f, i t} \\
& \left(\begin{array}{l}
u_{m, i} \\
u_{f, i}
\end{array}\right) \sim N\left[\left(\begin{array}{l}
0 \\
0
\end{array}\right),\left(\begin{array}{cc}
\sigma_{m, u}^{2} & \rho_{u} \sigma_{m, u} \sigma_{f, u} \\
\sigma_{f, u}^{2}
\end{array}\right)\right] \\
& \left(\begin{array}{l}
\epsilon_{m, i t} \\
\epsilon_{f, i t}
\end{array}\right) \sim N\left[\left(\begin{array}{l}
0 \\
0
\end{array}\right),\left(\begin{array}{cc}
1 & \rho_{\epsilon} \\
& 1
\end{array}\right)\right]
\end{aligned}
$$

Here, both the between-subject error $\mathbf{u}$ and the within-subject error $\boldsymbol{\epsilon}$ are assumed to be bivariate normal. $\rho_{u}$ and $\rho_{\epsilon}$ are crucial parameters, respectively, representing the correlation between the individual-specific effects, and the correlation between the within-errors, for the two members of the same couple. $\rho_{u}$ reveals the manner in which risk-attitude enters the matching process leading to couple formation. $\rho_{\epsilon}$ reveals the manner in which the two individuals are jointly influenced by unobserved "shocks" occurring in the time period leading up to the survey date.

Note that $u_{m, i}$ and $u_{f, i}$, the individual-specific risk attitude terms, are assumed to be fixed over time, and it is this assumption that enables us to interpret our estimate of $\rho_{u}$ in terms of a correlation in intrinsic risk attitudes at the time of forming the relationship, even though no data is available from that time. ${ }^{5}$

Suppressing $i$ and $t$ subscripts for a moment, it is noted that $y_{m}^{*}$ and $y_{f}^{*}$ are unobserved, but the relationships between these and the observed variables $y_{m}$ and $y_{f}$ are:

$$
\begin{array}{rlll}
y_{m}=1 & \text { if } \quad-\infty<y_{m}^{*}<\kappa_{1, m} & y_{f}=1 & \text { if }-\infty<y_{f}^{*}<\kappa_{1, f} \\
y_{m}=2 & \text { if } \quad \kappa_{1, m}<y_{m}^{*}<\kappa_{2, m} & y_{f}=2 & \text { if } \quad \kappa_{1, f}<y_{f}^{*}<\kappa_{2, f} \\
y_{m}=3 & \text { if } \quad \kappa_{2, m}<y_{m}^{*}<\kappa_{3, m} & y_{f}=3 & \text { if } \quad \kappa_{2, f}<y_{f}^{*}<\kappa_{3, f} \\
\vdots & & & \vdots \\
y_{m}=J \quad \text { if } \quad \kappa_{J-1, m}<y_{m}^{*}<\infty & y_{f}=J & \text { if } \quad \kappa_{J-1, f}<y_{f}^{*}<\infty
\end{array}
$$

The parameters $\kappa_{1, m}, \cdots, \kappa_{J-1, m}$ and $\kappa_{1, f}, \cdots, \kappa_{J-1, f}, j=1, \cdots, J-1$, are known as "cut-points". The absence of intercepts in the first two lines of Eq. 1 is a consequence of the cut-points all being free parameters.

The log-likelihood function for this model is constructed as follows. Let $P_{i t}\left(y_{m}, y_{f} \mid\right.$ $u_{m, i}, u_{f, i}$ ) be the joint probability (conditional on $u_{m, i}$ and $u_{f, i}$ ) that the responses of

\footnotetext{
5 On this point, we resort to empirical evidence on the stability of risk preferences provided by Sahm (2012) whose findings relate favorably to the assumptions we make.
} 
the male and female in the $i$-th couple in period $t$ are, respectively, $y_{m}$ and $y_{f}$. This conditional joint probability is given by:

$$
\begin{aligned}
& P_{i t}\left(y_{m}, y_{f} \mid u_{m, i}, u_{f, i}\right) \\
&= P\left(\left\{\kappa_{y_{m}-1, m}<y_{m, i t}^{*}<\kappa_{y_{m}, m}\right\} \cap\left\{\kappa_{y_{f}-1, f}<y_{f, i t}^{*}<\kappa_{y_{f}, f}\right\} \mid u_{m, i}, u_{f, i}\right) \\
&= \Phi_{2}\left(\kappa_{y_{m}, m}-x_{m, i t}^{\prime} \beta_{m}-u_{m, i}, \kappa_{y_{f}, f}-x_{f, i t}^{\prime} \beta_{f}-u_{f, i}, \rho_{\epsilon}\right) \\
&-\Phi_{2}\left(\kappa_{y_{m}, m}-x_{m, i t}^{\prime} \beta_{m}-u_{m, i}, \kappa_{y_{f}-1, f}-x_{f, i t}^{\prime} \beta_{f}-u_{f, i}, \rho_{\epsilon}\right) \\
&-\Phi_{2}\left(\kappa_{y_{m}-1, m}-x_{m, i t}^{\prime} \beta_{m}-u_{m, i}, \kappa_{y_{f}, f}-x_{f, i t}^{\prime} \beta_{f}-u_{f, i}, \rho_{\epsilon}\right) \\
&+\Phi_{2}\left(\kappa_{y_{m}-1, m}-x_{m, i t}^{\prime} \beta_{m}-u_{m, i}, \kappa_{y_{f}-1, f}-x_{f, i t}^{\prime} \beta_{f}-u_{f, i}, \rho_{\epsilon}\right)
\end{aligned}
$$

where $\Phi_{2}\left(z_{1}, z_{2}, \rho\right)$ is the bivariate normal cdf. The probability (conditional on $u_{m, i}$ and $\left.u_{f, i}\right)$ of the complete set of responses $\left(y_{m, i 1}, \ldots, y_{m, i T} ; y_{f, i 1}, \ldots, y_{f, i T}\right)$ for couple $i$ is:

$$
\prod_{t=1}^{T} P_{i t}\left(y_{m, i t}, y_{f, i t} \mid u_{m, i}, u_{f, i}\right)
$$

The likelihood contribution for couple $i$, that is, the unconditional joint probability of $y_{m}$ and $y_{f}$, is obtained by integrating both $u_{m}$ and $u_{f}$ out of Eq. 3:

$$
L_{i}=\int_{-\infty}^{+\infty} \int_{-\infty}^{+\infty}\left[\prod_{t=1}^{T} P_{i t}\left(y_{m, i t}, y_{f, i t} \mid u_{m}, u_{f}\right)\right] f\left(u_{m}, u_{f} ; \sigma_{m}, \sigma_{f}, \rho_{u}\right) \mathrm{d} u_{m} \mathrm{~d} u_{f}
$$

where $f\left(u_{m}, u_{f} ;, \sigma_{m}, \sigma_{f}, \rho_{u}\right)$ is the bivariate normal density function with mean vector zero, and covariance matrix as specified in the third line of Eq. 1.

Based on a sample $\left(y_{m, i t}, x_{m, i t}, y_{f, i t}, x_{f, i t} ; i=1 \cdots n, t=1 \cdots T\right)$, the loglikelihood is given by:

$$
\log L\left(\beta_{m}, \beta_{f}, \sigma_{m}, \sigma_{f}, \rho_{u}, \rho_{\epsilon}, \kappa_{1, m}, \cdots, \kappa_{J-1, m}, \kappa_{1, f}, \cdots, \kappa_{J-1, f}\right)=\sum_{i=1}^{n} \ln L_{i}
$$

Equation 5 is maximized using the method of maximum simulated likelihood (MSL) to give maximum likelihood estimates of all parameters. The use of MSL in this case requires two sets of Halton draws: one to simulate each of $u_{m}$ and $u_{f}$. The STATA code is available from the authors.

\section{Results}

Table 1 contains the results from the BPOP model, constructed in Sect. 3, which simultaneously models the risk attitude of males and females in couples. A number 


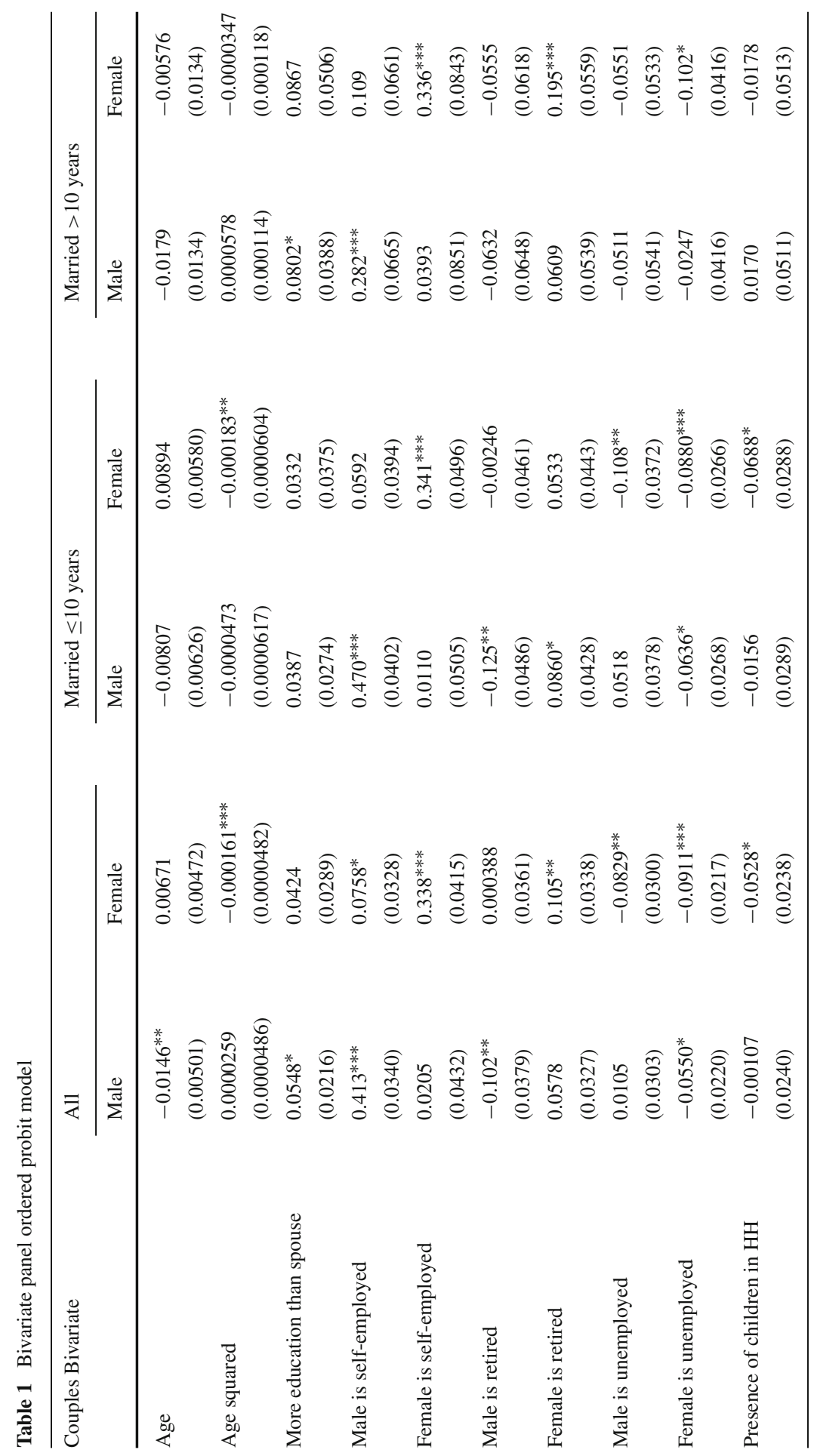




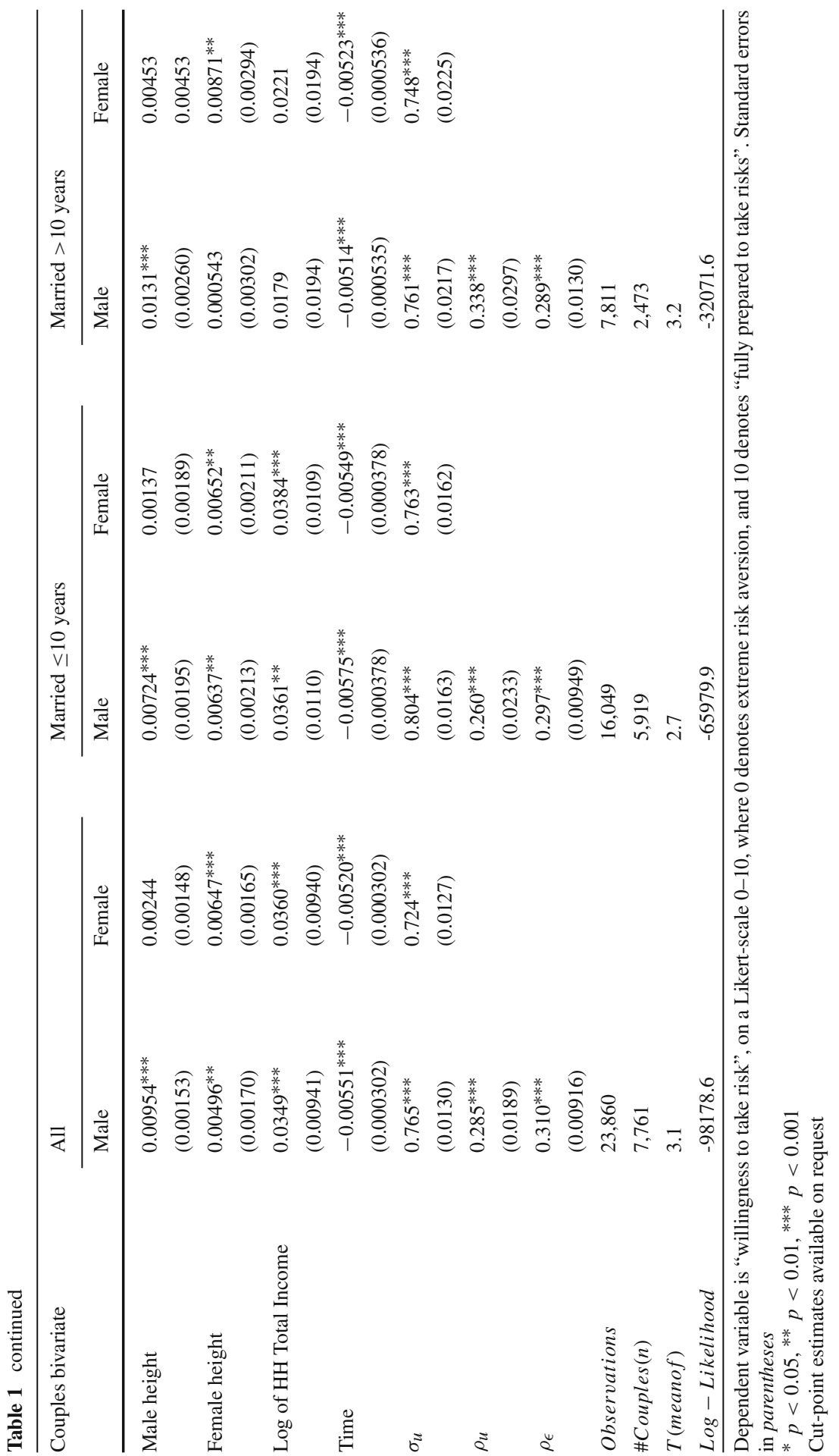


of explanatory variables are used, and these were introduced in Sect. 2. Some of the variables have a similar effect for both members of the couple; in other cases the effects differ between them.

The first two columns contain the results obtained from the whole sample. Age appears to have a negative effect on risk taking for both males and females. A dummy indicating whether the individual has more years of education than the spouse is included; this has a significant positive effect on risk-taking for males but not for females. Self-employment has the expected positive effect on risk-taking, as is welldocumented (e.g., see Ekelund et al. 2005). Retirement appears to have a significant positive effect for females but negative for males. The effect of unemployment is interesting. Although males' risk attitude appears to be unaffected by their own unemployment, it is found to depend negatively on the unemployment of their spouse. Females' risk attitude is negatively affected by both female and male unemployment. The presence of children has a significant negative effect on female risk taking, but has no effect on males. Dohmen et al. (2011) found a strongly significant effect of height on risk taking, and suggested explanations of this phenomenon. Here, we find that male height has a positive effect on risk taking for both partners, but that female height has a positive effect only for the female. The effect of income is positive for both partners. The coefficients of the variable "time" indicate that both males and females show a strongly significant decline in risk taking over the period covered by the sample. This might be attributed to the changing economic climate over the period 2004-2009.

As previously discussed, the key parameter in the model is $\rho_{u}$, the correlation between the individual-specific terms for males and females. This is estimated to be +0.285 with a standard error of 0.019 . The overwhelmingly strong significance of this coefficient is consistent with Becker's positive assortative mating theory.

An interesting possibility is that spouses "socialize" each other and that their preferences grow more similar with the accumulation of years of marriage. This would mean that the correlation parameter $\rho_{u}$ grows over time. In order to accommodate this idea, we have estimated the model separately for two groups of couples: those who have been married for 10 years or less; and those who have been married for more than 10 years. The results are shown in the final four columns of Table 1. The correlation parameter $\rho_{u}$ is estimated as larger for the second group $(+0.338$ as compared with +0.260 ; Wald test of this comparison gives $p$ value $=0.0081)$, and this is consistent with the "socialization" hypothesis. However, there is an alternative explanation for the difference. Marriages that last for more than 10 years must be seen as successful marriages and it may be that marriages are more successful if the spouses match more closely; couples who are not closely matched are more likely to experience a marriage breakdown in the early years, and are therefore likely to be under-represented in the second group. Such a selection process would of course explain the difference in parameters that we have uncovered.

The other correlation coefficient is $\rho_{\epsilon}$, and this represents the association between the within-error terms for the male and the female at the same point in time. This is estimated to be +0.310 with a standard error of 0.009 , when all data are used. We also see in the later columns of Table 1 that this parameter appears to be stable over years of marriage. As with the estimate of $\rho_{u}$, the estimate of $\rho_{\epsilon}$ is of overwhelming 
significance, indicating that the two members of the couple respond in similar ways to short-term shocks that have an impact on risk attitude.

\section{Conclusion}

Marriage is an important institution in human societies that brings about considerable societal benefits. The determinants of a successful marriage are clearly of great interest. Matching on the trait of risk attitude is the factor of interest in this paper.

We have combined the data sets from four cohort years of a statistically representative sample of the German population, in order to obtain a panel of couples. We have used these data to analyze the determinants of risk attitude for each member of the couple, and we have also considered the association between their risk attitudes. In analyzing the data set we have been careful to exploit the longitudinal nature of the data, and also to respect the ordinality of the dependent variable.

The key result relates to the significantly positive estimate of the parameter $\rho_{u}$, which has been interpreted in terms of "assortative mating" in the context of Becker's (1973) theory of marriage. First of all, it is by no means obvious that a positive value of $\rho_{u}$ is expected. Risk-sharing arguments (Chiappori and Reny 2006) would lead to the hypothesis that $\rho_{u}<0$. However, our data lead us to the opposite conclusion. This result builds on results reported by Dohmen et al. (2012), and also corroborates recent experimental findings regarding team-formation in decision tasks (Di Cagno et al. 2012), where, by a process known as homophily, individuals appear to seek out similarly minded team mates. An obvious difference from that experimental study is that, in the present study, we are interested in the formation of unions that are expected to last somewhat longer than the duration of an experiment.

Closer examination of our data has revealed that $\rho_{u}$ is larger for couples who have been married for longer. This has been explained in terms of a "socialization" process in which preferences grow more similar with time together. An alternative explanation was that unsuccessful marriages tend to break down in the early years and are therefore under-represented in the second sample. If this alternative explanation is valid, our overall conclusion is strengthened: not only is positive matching on risk attitude a precondition for marriage; it is a precondition for a successful marriage. Establishing which of these two explanations has greater validity is a promising avenue for further research.

The other correlation coefficient, $\rho_{\epsilon}$, has been interpreted in terms of "shared social environment", and is also significantly positive, implying that partners react in similar ways to shocks. $\rho_{\epsilon}$ has also been found to be stable over years of marriage. Note that separate identification of the two correlation coefficients $\left(\rho_{u}\right.$ and $\left.\rho_{\epsilon}\right)$ has been possible only because repeated data have been available on couples.

The two strongly significant estimates of the correlation coefficients, $\rho_{u}$ and $\rho_{\epsilon}$, underline the importance of adjusting for clustering when working with individual level data that are grouped into household clusters.

To our knowledge, we are the first researchers to have developed the BPOP model, which, given the rapidly growing interest in ordinal data, and the widening acceptance of Likert-scale data (Likert 1932) as a valid source of attitudinal information, we expect 
to be useful in other contexts. For example the BPOP could be used in a situation in which the respondent has been asked for their willingness to take risks in two different domains [e.g., financial and environmental, Riddel (2012)]. The only difference from the analysis of this paper is that the same vector of explanatory variables would apply to both responses. Once again the key parameters would be $\rho_{u}$ and $\rho_{\epsilon}$ : in this case they would capture the degree of consistency of risk attitude over domains.

Acknowledgments We acknowledge access to the German Socio-Economic Panel for use in this research under license number: 2596. We thank participants at Lancaster University Economics Dept seminar on 18 Jan 2012 for helpful comments especially Nick Snowden and Jim Taylor.

Open Access This article is distributed under the terms of the Creative Commons Attribution License which permits any use, distribution, and reproduction in any medium, provided the original author(s) and the source are credited.

\section{References}

Abdellaoui, M., l'Haridon, O., \& Paraschiv, C. (2013). Individual vs. couple behavior: An experimental investigation of risk preferences. Theory and Decision, 75(2), 175-191.

Aitchison, J., \& Silvey, S. D. (1957). The generalization of probit analysis to the case of multiple responses. Biometrika, 44(1/2), 131-140.

Bateman, I., \& Munro, A. (2005). An experiment on risky choice amongst households. The Economic Journal, 115(502), C176-C189.

Becker, G. S. (1973). A theory of marriage: Part I. Journal of Political Economy, 81(4), 813-846.

Becker, G. S. (1974). A theory of marriage. Economics of the family: Marriage, children, and human capital (pp. 299-351). Cambridge: National Bureau of Economic Research Inc.

Belot, M., \& Fidrmuc, J. (2010). Anthropometry of love: Height and gender asymmetries in interethnic marriages. Economics \& Human Biology, 8(3), 361-372.

Bonin, H., Dohmen, T., Falk, A., Huffman, D., \& Sunde, U. (2007). Cross-sectional earnings risk and occupational sorting: The role of risk attitudes. Labour Economics, 14(6), 926-937. Education and Risk Education and Risk S.I.

Chiappori, P.-A., Oreffice, S., \& Quintana-Domeque, C. (2012a). Fatter attraction: Anthropometric and socioeconomic matching on the marriage market. Journal of Political Economy, 120(4), 659-695.

Chiappori, P.-A., Oreffice, S., \& Quintana-Domeque, C. (2012b). Multidimensional matching with a potential handicap: Smoking in the marriage market. Mimeo.

Chiappori, P.-A., \& Reny, P. J. (2006). Matching to share risk. New York: Columbia University.

Clark, A. E., \& Etilé, F. (2006). Don't give up on me baby: Spousal correlation in smoking behaviour. Journal of Health Economics, 25(5), 958-978.

Daykin, A. R., \& Moffatt, P. G. (2002). Analysing ordered responses: A review of the ordered probit model. Understanding Statistics, 1(3), 157-166.

Di Cagno, D., Sciubba, E., \& Spallone, M. (2012). Choosing a gambling partner: Testing a model of mutual insurance in the lab. Theory and Decision, 72(4), 537-571.

Dittrich, R., Francis, B., Hatzinger, R., \& Katzenbeisser, W. (2007). A paired comparison approach for the analysis of sets of likert-scale responses. Statistical Modelling, 7(1), 3-28.

Dohmen, T., Falk, A., Huffman, D., \& Sunde, U. (2012). The intergenerational transmission of risk and trust attitudes. Review of Economic Studies, 79(2), 645-677.

Dohmen, T., Falk, A., Huffman, D., Sunde, U., Schupp, J., \& Wagner, G. G. (2011). Individual risk attitudes: Measurement, determinants, and behavioral consequences. Journal of the European Economic Association, 9(3), 522-550.

Dupuy, A., \& Galichon, A. (2012). Personality traits and the marriage market. IZA Discussion Papers 6943, Institute for the Study of Labor (IZA).

Ekelund, J., Johansson, E., Jrvelin, M.-R., \& Lichtermann, D. (2005). Self-employment and risk aversionevidence from psychological test data. Labour Economics, 12(5), 649-659.

Frechette, G. R. (2001a). Random-effects ordered probit. Stata Technical Bulletin, 10(59), 23-27. 
Frechette, G. R. (2001b). Update to random-effects ordered probit. Stata Technical Bulletin, 61, 12.

Hitsch, G., Hortaçsu, A., \& Ariely, D. (2010). What makes you click? Mate preferences in online dating. Quantitative Marketing and Economics, 8(4), 393-427.

Jaeger, D. A., Dohmen, T., Falk, A., Huffman, D., Sunde, U., \& Bonin, H. (2010). Direct evidence on risk attitudes and migration. The Review of Economics and Statistics, 92(3), 684-689.

Kano, S. (2008). Like husband, like wife: A bivariate dynamic probit analysis of spousal obesities. Mimeo.

Kooreman, P. (1994). Estimation of econometric models of some discrete games. Journal of Applied Econometrics, 9(3), 255-268.

Light, A., \& Ahn, T. (2010). Divorce as risky behavior. Demography, 47(4), 895-921.

Likert, R. (1932). A technique for the measurement of attitudes. Archives of Psychology (Vol. 140). New York: Columbia University Press.

McPherson, M., Smith-Lovin, L., \& Cook, J. M. (2001). Birds of a feather: Homophily in social networks. Annual Review of Sociology, 27(1), 415-444.

Oreffice, S., \& Quintana-Domeque, C. (2010). Anthropometry and socioeconomics among couples: Evidence in the united states. Economics \& Human Biology, 8(3), 373-384.

Powdthavee, N. (2009). I can't smile without you: Spousal correlation in life satisfaction. Journal of Economic Psychology, 30(4), 675-689.

Ribar, D. C. (2004). What do social scientists know about the benefits of marriage? A review of quantitative methodologies. IZA Discussion Papers 998, Institute for the Study of Labor (IZA).

Riddel, M. (2012). Comparing risk preferences over financial and environmental lotteries. Journal of Risk and Uncertainty, 45(2), 135-157.

Sahm, C. R. (2012). How much does risk tolerance change? Quarterly Journal of Finance, 2(4), 1250020.

Smith, M. D., \& Moffatt, P. G. (1999). Fisher's information on the correlation coefficient in bivariate logistic models. Australian \& New Zealand Journal of Statistics, 41(3), 315-330.

Wilson, S. E. (2002). The health capital of families: An investigation of the inter-spousal correlation in health status. Social Science \& Medicine, 55(7), 1157-1172. 